\title{
On Economics, Ethics, and Corporate Social Responsibility
}

\author{
Félix-Fernando Muñoz ${ }^{1}$, María-Isabel Encinar ${ }^{1}$, Carolina Cañibano ${ }^{2}$ \\ ${ }^{1}$ Department of Economic Analysis (Economic Theory and Economic History), \\ Universidad Autónoma de Madrid, Madrid, Spain \\ ${ }^{2}$ INGENIO (CSIC-UPV), Universitat Politècnica de València, Valencia, Spain \\ Email: felix.munoz@uam.es
}

Received April 11, 2012; revised April 20, 2012; accepted May 20, 2012

\begin{abstract}
This paper suggests that understanding questions such as those related to Corporate Social Responsibility (CSR) requires economic theorizing to include in its explanatory models the very fact that (economic) agents have their own distinctive conception of how reality ought to be (which implies making judgments of value). Under standard economic theorizing, the relationship between social or ethical values and economics is one of mere juxtaposition. Ethical and economic issues are being put together side by side in such a way that the anomalies pointed out by economics, which refer to the presence of goal paradoxes and the problem of altruism, etc., denote the presence of ethical issues within the processes of valuation and choice by agents. To surpass this relationship a change of perspective by means of the agents' action plans approach is proposed. The action plan approach allows to pass from a conception of economics understood as a technology-of-choice to economics understood as a theory of production-of-action. In particular, it is shown that the ethical dynamics of agents are capable of generating "ethical novelties", which consequently alter the agents' space of goals. Insofar as this is heavily influenced by CSR, the consequence is that CSR is neither strange to Economics nor a concept juxtaposed with the analysis of autonomous economic processes.
\end{abstract}

Keywords: Corporate Social Responsibility; Economics; Ethics; Agent Action Plan; Intentionality

\section{Introduction}

As standard economic theorizing has increasingly become a technology of choice, there is virtually no room for the integration of Ethics and Economics. Moreover, we have argued elsewhere that under the image of Economics as a technology of choice, the relationship between Ethics and Economics is one of mere juxtaposition [1]. Ethical and economic issues are being put together side by side in such a way that the anomalies pointed out by economics, which refer to the presence of goal paradoxes and the problem of altruism, etc., attest the presence of ethical issues within the processes of valuation and choice by agents. Standard economic theorizing does not provide a sufficiently coherent analytical base for integrating behaviors based on non-utilitarian or nonconsequentialist motivations.

However, this is the context in which thematic fields such as "ethical formation and economic behavior", "economy and social responsibility", etc., are usually posed [2]. As a result, the ethical problems present in agents' decisions, which owing to their very characteristics cannot be interpreted under the analytical focus of utilitarianism or the strictest consequentialism, would remain void of non-trivial economic explanation inasmuch as they are outside the domain of standard economic theory.

Economic rationality (the instrumental rationality inherent to the economic domain) is distinguished from other types of rationality (e.g. ethical rationality) as a characteristic of other spheres of social life. In this context, the goals pursued by agents (individuals and organizations), their evolution (which affects the connections between goals), their hierarchy and content and the agents' intentionality are not given sufficient consideration as dynamic elements of the economy.

In this paper, it is suggested that understanding questions such as those related to Corporate Social Responsibility (CSR) requires economic theorizing to include in its explanatory models the very fact that (economic) agents have their own distinctive conception of how reality ought to be (which implies making judgments of value). This generally goes beyond pure utilitarianism or consequentialism and determines the type of plans (strategies) they formulate and affects the decisions they undertake. This conception of what ought to be (which evolves as a result of the ethical dynamics of agents) can be seen in the definition, settlement and hierarchic struc- 
ture of the goals agents pursue as individuals and as organizations. These goals may be expressed in monetary terms (with a price) or are simply not susceptible to monetary expression.

The approach proposed in this paper implies a change of perspective: from a conception of Economics understood as a technology-of-choice to Economics understood as a theory of production-of-action. Section 2 includes a brief summary of certain relevant common topics of CSR literature that exemplify the problematic relationship between social responsibility and Economics. In Section 3, a conceptual view of the role and consequences of the agents' pursuit of goals on the development of new capabilities and new behavioral patterns, etc. is presented [3-6]. Accordingly, we introduce the concept of agents' action plans. In particular, it will be shown that the ethical dynamics of agents are capable of generating "ethical novelties”, which consequently alter the agents' space of goals. Insofar as this is heavily influenced by CSR, the consequence is (and this is the main thesis of the paper) that CSR is neither strange to Economics nor a concept juxtaposed with the analysis of autonomous economic processes. In Section 4, we show how a more comprehensive and systematic analysis of Economics and CSR can be developed: social responsibility is not an appendix or a mere technical expedient attached to economics, but rather an issue that refers naturally and necessarily to questions that may be answered from within an integrative approach, i.e. within a conception of Economics as a theory of production of action. The paper finishes with some concluding remarks.

\section{Economics, CSR and Choice}

There has recently been a significant increase in the concern about the ethical or non-ethical character of certain management models and business behaviors and their consequences. For example, in Spain sustainability reports have doubled since 2005. Moreover, according to a recent report by KPMG, $80 \%$ of the top companies in the world complete this procedure, as opposed to the $50 \%$ of three years ago [7]. Business forums, business schools and business journals insist on CSR and the ethical training of their executives, managers and employees [8]. Society supposedly requires modern companies and CEOs to provide more than maximum monetary efficiency in the management of resources [9].

Therefore, it is no longer sufficient to conceive corporations as decision units that merely select from a variety of given alternatives those that offer the maximum monetary profit, but rather it is necessary to consider corporations as organizations within a social environment for which they are also responsible.

The general recognition of the role of CSR is beyond discussion [10]. This recognition has given rise to a good number (and variety) of debates: for example, on the determination of the limits to CSR, the supply and demand of investments in socially responsible activities [11], etc. There have also been a variety of responses. Nevertheless, as a result of these debates, the existence of a problematic relationship between the economic and ethical-CSR discourses has been confirmed. Thus, CSR is introduced into the economic discourse in terms of the direct economic costs (more or less broad altruistic programs, internal or external to the company, which strengthen the corporation image) or indirect costs (defined as opportunity costs of the corresponding programs) companies have to assume.

Beside shareholders and stockholders, the old areas of concern for the entrepreneur are stakeholders (employees, shareholders, suppliers, clients, trade unions, institutions, universities, mass media, etc.) as agents to which the modern corporation is responsible. Moreover, companies are "forced" to add the socioeconomic and environmental element (clean and loyal production and commercial practices, corporation's co-responsibility regarding sustainable development) to this human group as facets a responsible corporation also has to take into consideration. (For example, the 2nd point of the European Commission Green Paper on CSR points out that CSR consists of "a concept whereby companies integrate social and environmental concerns in their business operations and in their interaction with the stakeholders on a voluntary basis" [12]). Do they total too many burdens for a company? If we accept that a company has to be responsible, how can the extension and density -where applicable- of the company's social responsibility be determined? The solution to this problem does not seem easy on a purely economic scale because it is not a merely utilitarian problem but also one of ethical behaviors.

In the literature on Ethics and Economics, multiple incompatibilities of actions described by standard economic theory appear as inherent to the representative economic agent in relation to many real actions (not only mainly economic) of people and organizations, thus giving rise to the literature of the casuistry of "the irrational" (altruistic actions, social responsibility, conflicts of interest, indecisions, etc.). Sen [13] is a classical reference on the internal inconsistency of preferences when revealing the choices made by the agent as the only way to accommodate "the anomalous" choices made by the agent on an analytical scale.

From a technical point of view, it is correct to affirm that any additional ethical consideration other than mere personal interest (e.g. altruism, motivations, etc.) would generate "irrational" choices or "anomalies" of problematic accommodation within the framework of standard economics [14]. The generalized use of utility as a con- 
cept that includes virtually everything agents want to value and the assumption that it is only valuable if it supposes an achievement have lead to the identification within a very widespread conception of economic theory of what is good for the agent (individual or organization) with all that reports positive achievements in terms of individual well-being, regardless of the value of the action itself [15]. The moral of achievement, based on a lax meaning of utility, has then been made compatible with the use of a concept of economic rationality identified with maximum self-interest or the principle of systematic egoism.

This kind of reasoning has led to the identification of standard economic theory as a technology of choice [16] in which the units of decision choose from a variety of given alternatives in an a-temporal context and use the maximization criteria of a subjective indicator of satisfaction susceptible to quantification (utility linked to consumption, pecuniary profits, etc.), which makes it possible to determine "quantitatively" how much of a goal is being achieved. The framework of standard economics is a-temporal: economic models (such as Walrasian models) are settled in a framework of logic, not historic time, leaving no room for substantial dynamic phenomena like expectations, money, innovation processes, institutional change and so forth [17].

From this viewpoint, the integration between ethics and economics is particularly problematic. In fact, under the technology-of-choice approach, the existing relationship between ethics and economics is one of mere juxtaposition: Ethics and Economics are put together in such a way that the anomalies indicated by the standard economic theory only serve to point out the presence of extra-economic ethical issues in the processes of valuation and choice of the agents. For example, although both common sense and empirical evidence suggest the contrary, the model of people as purely self-interest beings dominates management-related theories [18].

Despite the need to surpass these limitations by taking into account, for example, the ethical elements present in the strategic decisions or to integrate socially responsible behavior into a more general strategy for the company [19] that maximizes the long-term value [20], there is no sufficiently coherent analytical base in standard economics for integrating behaviors that differ from those based on egoistic or consequentialist motivations. As a conesquence, there is no room for explaining CSR or its extension or density. The "socially responsible" is seen as an additional restriction, a remora, which is imposed over the natural logic of economic processes [21]. If business ethics is conceived as a set of impositions and constraints, rather than motivating force of business behavior [22] the responsible entrepreneur will be responsible because he is called to philanthropy, regardless of what a "rational" or "economic" judgment dictates to him.

Nevertheless, most of these problems have to do with the meaning that is attributed to Economics. The precision of what is usually understood by Economics (by economic theory in particular) is a condition of possibility for progressing substantively in the intent to integrate ethics, economics and CSR. The understanding of questions as the role performed by ethics - and, therefore, CSR requires economics to incorporate into its explanatory models the irrefutable fact that agents have certain conceptions of ought to be (and in this technical sense, we will speak of ethics) that are idiosyncratic to them (that is, in this approach we give "ethics” a purely technical sense, which does not imply in itself any kind of moral relativism, but rather the qualification of a type of judgment), which determines the decisions they take. To explore the role played by individual ethical dynamics in economic processes, it will be necessary to go one step further: what is needed is to investigate the accurate meaning of what is "economic", i.e. of the object of study of economic theory. The concept of agent action plans will be extremely useful for this purpose.

\section{Agents Action Plans and Economic Dynamics}

\subsection{Agents Action Plans}

By human rational action, it is meant that action is formed and deployed according to reason; otherwise, the agents' action is essentially planned, i.e. according to plans of action. In order to analyze an agent's real action as an indissoluble and dynamic whole, an examination of the analytical structure of agency action from the "action plan” framework is proposed. The concept of action plan is not new in economics. It can be found in the work of economists of very different traditions, such as Keynes [23], Hicks [24], Debreu [25], Boulding [26], Lachman [27], Metcalfe [28], etc.

To shed light on a wide range of complex phenomena, the action plan is proposed as a suitable unit of selection. The "action plan approach" is a theoretical framework that connects micro- and meso-analytical levels [29] by allowing the consideration of the role of goals and intentionality in the explanation of action [30,31] (obviously not all human-individual or organizational-is necessarily planned. However, it is this characteristic note of human action why action is rationally intelligible).

From this standpoint, economic dynamics may be understood in a complementary way to that previously exposed as the process of generation, adoption and an attempted interactive deployment of the agents' plans of action and the resulting products [32]. An action plan is the agent's projective linkage of means to goals (or ends). The very nature of action plans is the projective character 
of the ordering involved. At each instant of time, an action plan may be interpreted as a template, blueprint or guide for action that projectively connects elements of a different nature: something the agent wants to achieve (goals or purposes) with the means the agent "knows" afford him success.

The action plans individuals elaborate are characteristic to them. Take, for example, an individual's plan for a trip. They can also be plans that articulate the action and coordinate the goals of groups of people (all types of organizations and societies). Take, for example, a family's plan of a trip, a company's business plan, a plan of the European Commission to reach the objectives of Lisbon, a country's development plan, etc.

An action plan is a system of connections whose elements are linked in a special manner; it is the projective ordering of means to achieve ends located in the imagined future. This concept shows the direction of action: agents (individuals or organizations) determine their goals and their connection with means and project the sequence for achieving them. Accordingly, they need to order their actions (according to their knowledge, experience, perceptions, creativity, beliefs and entrepreneurship, etc.) in order to achieve purposeful goals. An action plan is a rather general open structure; it can include routine patterns of behavior, strategic designs and monitoring and valuation procedures, etc.

A plan can also refer to its goals at several points in the future, represent hierarchical dependencies between goals and actions with as many analytical moments in time as may be required, as well as alignments of goals with other individuals' plans (e.g. as complex as desired). Its projective character refers not only to the fact that historic time (and timing) play central roles in explaining human action, but also that actions and goals need to be imagined before they are deployed by agents. Imagination plays a central role in this approach. As Loasby [33] states, "imagination always operates by making new connections, thereby creating new structures: imagination creates order. There seem to be three motives for doing so: as a direct challenge to an existing order, as a response to a breakdown of order, and as an attempt to colonize a terra incognita."

These sets of means and goals (the elements of the system "action plan") can be manifold. The set of actions and goals linked projectively by means of an action plan may contain different kinds of elements: material or immaterial elements localized at different moments in time (obviously, not all at the same time); elements with a monetary price (in official currency) or without a monetary price (a subjective level of satisfaction of a need); etc. Action plans are an analytical open representation of projective agency action because means and goals are not given a priori, but rather produced by the agents them- selves. These analytical constructions enable the depiction of any kind of action plan (such as a planned trip, a business plan, a strategic plan, a CEC plan to implement the objectives of the Lisbon agenda, etc.) with structures of hierarchical dependence between goals and with as many analytical periods of time as necessary (properties and representations of the structure of action plans using simple graphs can be found in [34]).

Plans are pervasive and the importance of action plans for economic theorizing is not new. Agencies (individuals and organizations) make plans and planning (an activity in itself) implies making connections.

\subsection{Some Examples}

In order to have a more accurate idea of the meaning of an action plan, the following figure shows an open representation of one of these plans.

Figure 1 represents an action plan of an agent (an individual, a group or an organization) at instant $t$. The plan depicted here consists of executing actions $a_{1}, a_{2}$ and $a_{3}$ at instant $t$; executing $a_{4}$ and $a_{5}$ in order to reach goal $g_{1}$ at the next (analytical) instant $(t+1)$; and finally reach goals $g_{2}, g_{3}$ and $g_{4}$ in $(t+2)$. The underlined actions and goals $\left(a_{1}, a_{5}, g_{1}\right.$ and $\left.g_{2}\right)$ represent actions and goals "with a price" (for example, actions such as purchasing and selling, which have a monetary revenue, etc.; and goals such as reaching a rate of return, a level of sales, etc.); while the non-underlined actions and goals $\left(a_{2}, a_{3}, a_{4}, g_{3}\right.$ and $\left.g_{4}\right)$ are actions and goals "without price" (thinking, "do nothing", etc.); and goals such as learning something, protecting the natural environment, etc.

This type of representation can be adapted to contain any kind of action plan. Thus, for example, the same graphs may be used to introduce elements related to CSR. Let us suppose that the represented plan consists of the set of actions and goals of a financial firm that awards microcredit. The financial firm begins by: raising funds $\left(a_{1}\right)$; reuniting a group of people who wish to set up in business and have no access to formal credit $\left(a_{2}\right)$; and providing them with the required knowledge and capabilities $\left(a_{3}\right)$ at instant $t$ in order to achieve the goal $\left(g_{1}\right)$ at $t+1$, i.e. acquiring the means necessary to carry out the productive activity in question, so that, thanks to the financial support and financial services contributed by the

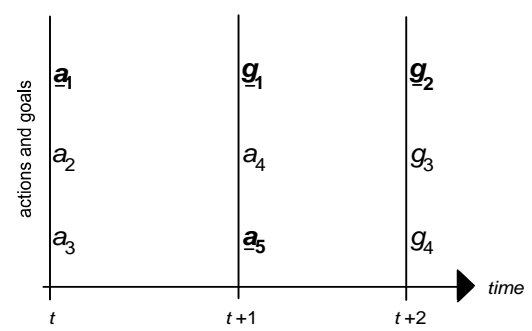

Figure 1. Representation of an action plan (see [35]). 
financial organization $\left(a_{5}\right)$ the selected group of people enrolled in the project $\left(a_{4}\right)$ are able to reach a level of income $\left(g_{2}\right)$ at instant $t+2$ to enable the independent personal and social development of the people, who receive the financial support $\left(g_{3}\right)$, thus break one of the worst vicious circles of poverty $\left(g_{4}\right)$.

At this point the reader may ask the following questions: if Economics refers to all this, what do the characteristic purpose of economics as a reality and that of economic theory as a science comprise? If the conception of "the economic" characteristic of economic theory is what is proposed above (a theory of human action and its products), may we claim that contemporary economic theory is pure economicism? However, a meaning of what is "economic" would be economicism if it implied that the elements "with a price" in action plans had preeminence over all the other elements in the said plans; otherwise, it would imply that all the elements considered in action plans were "economic" in the popular sense of elements "with a price". In our argument, the meaning of what is "economic" does not involve or imply any such thing; although, as is evident, it would not exclude it if it were the case.

However, the current meaning attributed to what is "economic" refers to $a_{1}, a_{5}, g_{1}$ and $g_{2}$, i.e. to the elements "with a price", but not to the others. Nevertheless, within the approach proposed here, the whole structure of plans, and, therefore, all their constitutive elements are "economic" in the sense we attribute to economic theory here (further explained below). It should be noted that, despite this fact, it would not be possible to isolate the elements $a_{1}, a_{5}, g_{1}$ and $g_{2}$ from the rest without considering their role in the context of the action plan.

\subsection{Technology of Choice \& Production of Action}

Speaking about plans (based on the analytical openness of both means and goals of action) implies the definitive abandonment of the timeless framework of the "technology of choice". The paradox of a timeless approach as an analytical basis for the explanation of processes that are necessarily deployed in time is solved through the dynamic openness of the actions and goals pursued by agents. Robbins' [36] definition of economics is essentially correct, but it is not sufficient.

Within the action plan approach, agents' rationality depends on the goals and motivations they pursue. What directs economic activity is not only economic calculus, but also the possibility of developing a true open rationality, the rationality of the unexpected in a context of radical uncertainty [37].

The concept of action plan allows us to move from a conception of economics as a technology of choice to economics as a theory of production of action (the latter becomes a condition of possibility for implementing a more substantive approach to "economics and CSR" issues. Indeed, economic theory is a particular approach to the study of rational human action in general, where the specificity is not in its object of study (the human action in general), but rather in the research method (and that consists of rationally studying the causal structures that link together the "adopted action plans" and the individual and collective "results produced" by the interaction of these plans. Planning itself is not economic action; planning is a part of action-it is in fact an activity. It is the interactive deployment of these plans drawn up by agents and partly configures the economic (and social) general dynamics.

Of course, not all human action is planned. The total action of a person (his/her real action) is made up of two elements: planned action and unplanned action. Planned action is not unimportant, residual or trivial; nor is it closed to rational knowledge. Feelings, emotions, instincts, beliefs, etc. play a very important real role in a person's action. However, what deserves our attention as economists is that part of the action that is the result of deliberation [38]. Nevertheless, and despite being a part of the total action, the planned action introduces a series of fundamental dynamic elements that help us apprehend, among other things, the dynamical role of the intentionality in action.

\section{Economics, Ethics, and CSR: Towards an Integrated Approach}

\subsection{Economics and Ethics}

The concept of action plan incorporates a series of elements that are extremely important for explaining rational human action. Let us consider two fundamental elements: the goals of action and the projective character of action. Agents choose their action goals after taking into account a multitude of factors: psychological, social, cultural, ethical, etc. These plans are constituted using the imagination, considering that the goals pursued are located in a future that is imagined by the agent.

It can be said that agents invent the future towards which they want to focus their actions [39]. This idea is valid when a goal in the very near future or in the medium or long term is considered. The opportunities for acting in a certain way (e.g. entrepreneurial) are not hidden in some place of the reality waiting to be discovered by entrepreneurs or visionary individuals, but initially they are in the imagination of the agents (regardless of whether or not these opportunities later acquire the materiality of a written document, etc.). In the business world, this projective activity is especially evident in business strategy formulation and selection processes. 
The connections between means and goals depend logically on what the agents know or think they know, i.e. on cognitive dynamics. Cognitive dynamics refer to the understanding agents (individuals or organizations) have of reality, where their understanding is condensed into representation systems created by the agents themselves (based not only on the traffic of scientific and technical representations, but also on beliefs the agents have on what the reality is, as well as the evolution of their understanding). However, action plans materialize on the basis of the objectives, on the goals the agents want to reach. These goals are, in fact, those that guide action and furnish it with sense. We are therefore in a position to make an analytical distinction between the agents' perception of what reality is or could be in the future (the agents' cognitive dynamics) and their conception of what the reality ought to be, i.e. their ethical dynamics.

Both dynamics, along with the cultural dynamics of the society in which agents carry out their activities, modify the content and forms of the agents' action plans and, consequently, generate new realities. These realities contrast what agents previously conjecture in their action plans (ex ante) and what they agents (ex post) understand as actually happened. The imbalances between the courses of action and the anticipated results of action and what finally actually happens activate revision mechanisms (learning processes) regarding the agents' plans as well as the way they (re)formulate their plans. As a consequence of this feedback, economic processes are complex processes.

It is important to emphasize here that if one agent (or several agents) change (modify, alter, adapt, etc.) their goals (goals themselves and/or their hierarchic disposition), it implies first of all that the content and form (structure) of their plans are modified and, secondly, that the interactive deployment of the new plans generates new realities. In fact, the introduction of new goals [40] does not only alter the agents' spaces of objectives but also induce new types of actions and capabilities.

It is also fundamental to determine that the concept of ethical dynamics referred here does not have any aprioristic content in the sense that it does not imply any type of previous judgment about what is "good" or "bad". The concept of ethical dynamics here simply recognizes that the agents act by projecting their action and, mainly, choosing their goals on the basis of their conception of how things ought to be.

The purpose of Economic Theory is not to value the goodness or badness of certain behaviors, change processes or the novelties that arise; this is the domain of Ethics. However, Economics does consider what the agents conceive as ought to be (and not only what they understand as is) because this determines decisively how agents form and select their action plans and, therefore, the actions they will take to achieve their goals and the consequences they have for the physical and natural world and the human and socio-cultural domain. And this points out the exact location of the element of connection between the ethical and economic domains. Economic action presupposes Ethics; however, economic actions do not prescribe ethical contents.

To move over from a conception of economics understood as technology-of-choice to economics as theory of production-of-action helps us recognize the decisive role of ethical dynamics in the explanation of the characteristic purpose of the analysis of Economic Theory (explaining why agents choose certain courses of action and not others, and the consequences of the interactive deployment of the said courses of action within the social milieu), as well as its eventual integration within the economic domain. Only in this way is it possible to overcome the mere juxtaposition between Ethics and Economics and the questions related to businesses ethics.

\subsection{CSR and Economics}

Let us now briefly examine the relationship between Economics and CSR from the point of view proposed here. Economic agents (individuals or organizations) not only differ from each other in their knowledge and capabilities but can also be distinguished by the goals to which they aspire. For example, with quite similar capabilities, different individuals or organizations may have very different aspirations. It is not our intention here to examine whether the particular prescriptive content of the goals each agent pursues is good or bad. The point here is to indicate that the content of the agents' goals also has an ethical origin. This specific content is an essential constituent part of the agents' action, and it cannot be explained as a mere result of knowledge and learning processes, but is direct and intimately tied to the conceptions of those agents and their ethical formation.

The "socially responsible" entrepreneur is not less rational than the entrepreneur who only maximizes economic profit. In a sense, both of them are maximize and rational. The difference between them is not the behavioral rule they observe or if one of them acts economically and the other does not. Both types of entrepreneurs set the formal achievement of a goal that is also hierarchically superior to their other goals and for that reason, this goal acts as the norm of their own action plans. Both types of entrepreneurs define their action plans by setting the goal (for an individual or a group) they want: they want to produce that goal. Thus, both types of agents are equally rational in that sense.

A common statement in standard economics is that business efficiency is measured by a definition of the excess of revenues over expenses. Regardless of the truth 
or falseness of such a claim, this statement requires, among other conditions, agents to have previously elevated the attainment of the maximum amount of money into the hierarchically dominant goal of business. Were this not the case, if the hierarchically dominant goal were not the attainment of the maximum amount of money, the place of that goal would necessarily be taken up by a different goal, which is perfectly rational according to what has been said above in this paper.

The difference between an entrepreneur that maximizes his/her profits and his/her socially responsible counterpart would lie in the specific prescriptive content of the hierarchically superior goals in their respective action plans. For the former, it would be the maximum difference between his/her revenues and their costs; for the latter, it would be a socially responsible aim. They are the agents (individuals or organizations) who decide their goals of action and the place they have in their action plans regardless of their goals or actions with or without price. The fact that certain goals or actions (and no others) were (or were not) considered in their action plans is explained by each agent's ethical conceptions, i.e. by his/her own ethical dynamics.

Thus, moving from a conception of economics as technology of choice to a conception of economics as production of action reveals the decisive role of ethical dynamics, entrepreneurship and CSR in the explanation of economic processes. The entrepreneur's most important role is the production of new courses of action, i.e. producing new economic situations. This is the very nature of entrepreneurship in the context of a theory of production-of-action: entrepreneurship requires a focus on a transforming goal. This focus involves learning processes but it can also imply the emergence of completely new intentions and actions that are not explained solely by mere knowledge acquisition processes.

Take, for instance, the interesting case of Grameen Bank. This bank has reversed conventional banking practice by removing the need for collateral and it has created a banking system based on mutual trust, accountability, participation and creativity. Muhammad Yunus, the founder of Grameen Bank considered that financial resources ought to be made available to the poor under terms and conditions that are both appropriate and reasonable. Those ideas were at the origins of the micro-credit system and they modify the contents and forms of the spaces of agents' action and, consequently, generate new realities [41].

From the production of action point of view, it is easy to see why the socially responsible entrepreneur is rational: human action, qua rational, within human constraints is intended action: there must be goals (reasons) for acting. As any other agents in the economy, entrepreneurs decide what their goals of action are (and what they are not) and which place they should be given in their action plans regardless of whether or not their goals or actions are attached to a price.

Finally, the role of CSR in the global dynamics of the economically represented society is indicated by the types of actions deployed in interaction by the members of society, but mainly by the goals inserted within the agents' action plans. What makes something be considered good or bad, etc. is not the content of the prescripttions, but the personal practical decision processes: ethics is internalized in human action, although other sources of norms would exist.

The entrepreneur will be socially responsible if his action plans place special importance on "ethical" goals. Figure 2 offers a graphic summary of this idea.

\section{Concluding Remarks}

CSR may be introduced for a variety of reasons; even as a result of a purely strategic or egoistic calculation [20]. But it may also respond to other motivations: it may be a consequence of a legal imposition or a consequence of pressure from certain social groups, which implies the threat of a legal or social penalty, or as a result of conversion (e.g. companies in the non-profit sector). In any case, this will be seen in the role played by the socially responsible goals in the hierarchy of goals of a person or organization and in the density and intensity of the social traffic of this type of goal. Furthermore, it will show itself in the type of plans or courses of action these agents undertake in interaction with others, giving rise to specific effects.

There is nothing in the nature of economic affairs that presupposes that elements with a price have an invariant natural autonomy, i.e. that the said elements follow a logic (a rationality) on their own and regardless of the other spheres that make up human action in society. If this were really so, we would again be in the presence of a relationship of mere juxtaposition between Ethics and Economics, where Ethics and CSR would be no more

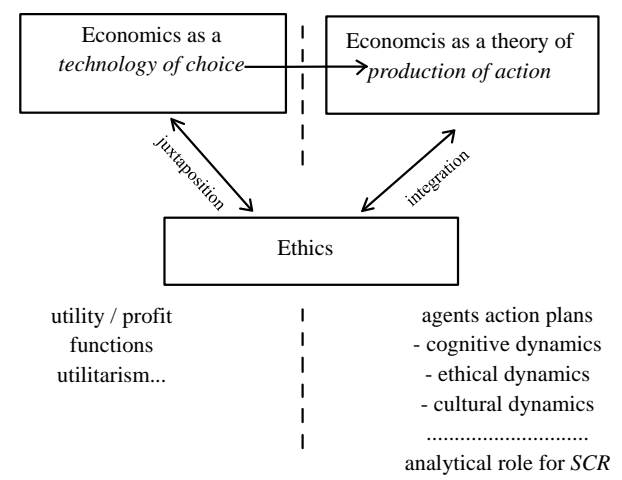

Figure 2. Relationship between different conceptions of ethics and economics. 
integrated with Economics and where the only role played by CSR and the ethical training of managers, employees and entrepreneurs, etc. would be to mitigate the undesired consequences of the said autonomous economic processes. A change of focus on the conception of Economics such as the one proposed in this paper proves that this is not necessarily the case. The fact that the specific content of goals (whatever it may be), which depends on individuals' beliefs, knowledge and intentionality, etc., may produce its effects through the actions of the individuals themselves also implies the possibility of a more integrated relationship between Ethics, Economics and CSR.

\section{REFERENCES}

[1] M. I. Encinar, J. L. Cendejas and F. F. Muñoz, "On the relationship between Ethics and Economics," Cuadernos de Economía, Vol. 29, No. 76, 2006, pp. 93-118.

[2] F. Weyzig, "Political and Economic Arguments for Corporate Social Responsibility: Analysis and a Proposition Regarding the CSR Agenda,” Journal of Business Ethics, Vol. 86, No. 4, 2009, pp. 417-428. doi:10.1007/s10551-008-9855-4

[3] R. R. Nelson, "Evolutionary Social Science and Universal Darwinism,” Journal of Evolutionary Economics, Vol. 16, No. 5, 2006, pp. 491-510. doi:10.1007/s00191-006-0025-5

[4] R. R. Nelson, "Bounded Rationality, Cognitive Maps, and Trial and Error Learning," Journal of Economic Behavior \& Organization, Vol. 67, No. 1, 2008, pp. 78-89. doi:10.1016/j.jebo.2007.06.002

[5] G. Dosi, R. R. Nelson and S. G. Winter, "The Nature and Dynamics of Organizational Capabilities,” Oxford University Press, Oxford, 2000.

[6] R. N. Langlois, "The Dynamics of Industrial Capitalism. Schumpeter, Chandler, and the New Economy," Routledge, London, 2006.

[7] KPMG, "KPMG International Survey of Corporate Responsibility Reporting 2008,” 2008.

http://www.kpmg.com/global/en/issuesandinsights/article spublications/pages/sustainability-corporate-responsibilityreporting-2008.aspx

[8] A. Lindgreen, V. Swaen and F. Maon, "Introduction: Corporate Social Responsibility Implementation,” Journal of Business Ethics, Vol. 85, Suppl. 2, 2009, pp. 251-256. doi:10.1007/s10551-008-9732-1

[9] D. B. Bielak, S. M. J. Bonini and J. M. Oppenheim "CEOs on Strategy and Social Issues,” The McKinsey Quarterly, 2007, pp. 1-8 (accessed 20 July 2010).

http://www.mckinseyquarterly.com/CEOs_on_strategy_a nd_social_issues_2056

[10] A. B. Carroll, “Corporate Social Responsibility,” Business and Society, Vol. 38, No. 3, 1999, pp. 268-299. doi:10.1177/000765039903800303

[11] A. McWilliams and D. Siegel, "Corporate Social Responsibility: A Theory of Firm Perspective,” Academy of Man- agement Review, Vol. 26, No. 1, 2001, pp. 117-127.

[12] CEC, "Promoting a European Framework for Corporate Social Responsibility. Green Paper,” 2001.

http://ec.europa.eu/employment_social/soc-dial/csr/green paper_en.pdf

[13] A. K. Sen, “Internal Consistency of Choice,” Econometrica, Vol. 61, No. 3, 1993, pp. 495-521. doi:10.2307/2951715

[14] S. Zamagni, Ed., “The Economics of Altruism. International Library of Critical Writings in Economics,” Edward Elgar, Cheltenham, 1995.

[15] A. K. Sen, “On Ethics and Economics,” Blackwell, Oxford, 1987.

[16] C. Cañibano, M. I. Encinar and F. F. Muñoz, "Evolving Capabilities and Innovative Intentionality: Some Reflections on the Role of Intention within Innovation Processes,” Innovation: Management, Policy \& Practice, Vol. 8, No. 4-5, 2006, pp. 310-321.

[17] G. S. L. Shackle, "Epistemics and Economics," Cambridge University Press, Cambridge, 1972.

[18] S. Ghoshal, "Bad Management Theories Are Destroying Good Management Practices,” Academy of Management Learning \& Education, Vol. 4, No. 1, 2005, pp. 75-91. doi:10.5465/AMLE.2005.16132558

[19] M. E. Porter and M. R. Kramer, "The Competitive Advantage of Corporate Philanthropy,” Harvard Business Review, Vol. 80, No. 12, 2002, pp. 56-58.

[20] M. C. Jensen, "Value Maximization, Stakeholder Theory, and the Corporate Objective Function," Business Ethics Quarterly, Vol. 12, No. 2, 2003, pp. 235-256. doi: $10.2307 / 3857812$

[21] M. Friedman, "The Social Responsibility of Business Is to Increase Its Profits,” New York Times Magazine, 13 September 1970, pp. 32-33.

[22] R. C. Solomon, "Corporate Roles, Personal Virtues: An Aristotelian Approach to Business Ethics,” Business Ethics Quarterly, Vol. 2, No. 3, 1992, pp. 317-339. doi:10.2307/3857536

[23] J. M. Keynes, “The General Theory of Employment, Interest and Money,” MacMillan, London, 1936.

[24] J. R. Hicks, "Value and Capital: An Inquiry into Some Fundamental Principles of Economic Theory," Clarendon Paperbacks, Oxford, 1939.

[25] G. Debreu, "Theory of Value: An Axiomatic Analysis of Economic Equilibrium,” Yale University Press, New Haven, 1959.

[26] K. Boulding, “What Is Evolutionary Economics?” Journal of Evolutionary Economics, Vol. 1, No. 1, 1991, pp. 9-17. doi:10.1007/BF01202334

[27] L. Lachmann, "Vicissitudes of Subjectivism and the Dilemma of the Theory of Choice. Expectations and the Meaning of Institutions,” In: D. Lavoie, Ed., Essays in Economics by Ludwig Lachmann, Routledge, London and New York, 1994, pp. 218-228.

[28] J. S. Metcalfe, "The Entrepreneur and the Style of Modern Economics,” Journal of Evolutionary Economics, Vol. 14, 2004, pp. 157-175. doi:10.1007/s00191-004-0210-3 
[29] K. Dopfer, J. Foster and J. Potts, "Micro-Meso-Macro," Journal of Evolutionary Economics, Vol. 14, No. 3, 2004, pp. 263-279. doi:10.1007/s00191-004-0193-0

[30] J. R. Searle, "Intentionality: An Essay in the Philosophy of Mind,” Cambridge University Press, Cambridge, 1983. doi:10.1017/CBO9781139173452

[31] J. R. Searle, "Rationality in Action," The MIT Press, Cambridge, 2001.

[32] F. F. Muñoz, M. I. Encinar and C. Cañibano, "On the Role of Intentionality in Evolutionary Economic Change,” Structural Change and Economic Dynamics, Vol. 22, No. 3, 2011, pp. 193-203. doi:10.1016/j.strueco.2011.04.002

[33] B. J. Loasby, "Imagination and Order," The DRUID Summer Conference 2007 on Appropriability, Proximity, Routines and Innovation, Copenhagen, 18-20 June 2007. http://www.druid.dk

[34] M. I. Encinar and F. F. Muñoz, "On Novelty and Economics: Schumpeter's Paradox,” Journal of Evolutionary Economics, Vol. 16, No. 3, 2006, pp. 255-277. doi:10.1007/s00191-006-0018-4
[35] R. Rubio de Urquía, “Una Introducción Sistemática al Tema Economía y Responsabilidad Social,” In: P. Giménez, C. de la Calle and L. Climent, Eds., Persona y Sociedad. Las dos Caras del Compromiso, Universidad Francisco de Vitoria \& Cátedra de Responsabilidad Social Corporativa del Grupo Santander, Madrid, 2007, pp. 25-65.

[36] L. Robbins, "An Essay on the Nature and Significance of Economic Science,” Macmillan, London, 1932.

[37] F. Knight, "Risk, Uncertainty and Profit," Houghton Mifflin, Boston, 1921.

[38] L. Mises, "Human Action: A Treatise on Economics," Hodge, London, 1949.

[39] B. J. Loasby, "Knowledge, Institutions and Evolution in Economics,” Routledge, London, 1999. doi:10.4324/9780203459096

[40] C. Cañibano, M. I. Encinar and F. F. Muñoz, "Ethical Novelty: new insights into economic change,” 2006. http://econpapers.repec.org/paper/uamwpaper/200603.htm

[41] M. Yunus, "Vers un Monde sans Pauvreté,” Jean-Claude Lattès, Paris, 1997. 